\title{
School Community Connectedness and Family Participation at School
}

\author{
Meghan K. Dove ${ }^{1, *}$, Jennifer Zorotovich ${ }^{1} \&$ Katy Gregg ${ }^{1}$ \\ ${ }^{1}$ School of Human Ecology, Georgia Southern University, Statesboro, Georgia, United States \\ *Correspondence: School of Human Ecology, Georgia Southern University, Statesboro, Georgia, United State. Tel: \\ 1-912-478-1521. E-mail: mdove@georgiasouthern.edu
}

Received: January 18, 2018

Accepted: February 5, $2018 \quad$ Online Published: February 20, 2018

doi:10.5430/wje.v8n1p49

URL: https://doi.org/10.5430/wje.v8n1p49

\begin{abstract}
Family involvement in a child's education is a complex system that extends beyond the presence of partnerships between families, schools, and the community (Epstein, 2011). By measuring families' feelings of connectedness and membership to the school community, this study explores families' motivations for participating in their child's learning and development at school. Results suggest that a family's sense of connectedness to their child's school community may be related to their level of participation. Findings are discussed in terms of implications for educational communities emphasizing the power of families' community connectedness within the schools and expanding on the ways to enhance family involvement and participation.
\end{abstract}

Keyword: community connectedness, family participation, parental involvement, school

\section{Introduction}

This purpose of this study is to explore how families' sense of connectedness to the school community relates to their participation in school activities and events. A sample of 218 parents with kindergarten to fifth grade students completed surveys addressing their feelings of being connected to their child's school community and participation practices within the child's school. The authors predicted a positive correlation between sense of connectedness to a school community and family participation in school activities and events.

\subsection{Theoretical Perspectives}

A school community consists of the individuals and systems that influence the learning and development of the children in that school. This includes, but is not limited to, families, teachers, administrators, and school policies. In order to be inclusive of caregivers and other family members directly involved in the child's education, family is used rather than parent when discussing those involved in the child's education in this study. Epstein's (2011) theory of family-school connections describes the processes and contexts surrounding a child's education as "overlapping spheres of influence of family, school and community on children's learning" (p. 28). Epstein's (2011) external and internal structures model of family involvement illustrates the processes and complex relationships between home, school, and the community. The external view of the model shows how the unique experiences, philosophies, and practices of families, schools and the community can impact family participation. Although this external structure provides a framework for understanding broader influences on communities, the internal view of the structure demonstrates the interpersonal relationships within the school that can influence family participation within school events and activities, which is the focus of this study.

The internal structure includes family-teacher interactions and the broader school-family interactions. School-family interactions include those outside of the child's classroom, such as school administrators. All of these relationships form the foundation of a school community. There is considerable variation in the ways in which these interactions transpire, often dependent on resource availability and teachers' propensity to utilize those resources (Bird, 2006; Selwyn, Banaji, Hadjithoma-Garstka, \& Clark, 2011; Ramirez, 2001; Smith, Wohlsetter, Kuzin, \& DePedro, 2011; Telem \& Pinto, 2006). Further, these family-teacher relationships are influenced by families' beliefs of their abilities to extend learning at home to support their children's development on a personal level (McKenna \& Millen, 2013). The nature of this relationship with the teacher can influences a family's acceptance of invitations to participate. For instance, Bower and Griffin (2011) found that teacher invitations were not effective at increasing family involvement and participation without there first being a relationship between teachers and the child's family. Quality of 
family-teacher relationships and a sense of community connectedness may impact overall family participation and may be influenced by both perceptions and experiences of families and school personnel.

\subsection{Community Connectedness}

Often the idea of a community brings to mind geographic locations, an event bringing people together, or a specific group of individuals with similar interests. However, communities are much more complex than a group of people. While communities require a unifying element, based on Mancini and Bowen's (2013) work, ultimately communities are built on capacity and connections. A community's capacity is made up of two elements: members' feelings of shared responsibility, which is their concern for the wellbeing of the community, and the collective competence of the members, which is made up of their abilities to take action in enacting change. Community capacity is mobilized through formal and informal network connections and the sense of connectedness within and between these networks (Mancini, Bowen, Ware, \& Martin, 2007). Research has shown that community connectedness is broken into three areas: efficacy, engagement, and participation. Efficacy is a community's capacity to enact change, engagement is the interpersonal closeness of the members, and participation is involvement in civic affairs. While Mancini and colleagues discussed these within various community make ups, these three areas are also the core to developing a connected school community.

A noted previously, a school community is created as family members, teachers, administrators and staff partner together on guiding and supporting the development and learning of children. The school community's connectedness is established as they build trust and share the responsibility of educating children using their social capital within their formal and informal networks. Within a school community, families feeling connected to the formal network of the school and the staff and to the informal networks of other families may either enable or hinder families participation in events and activities at their child's school; one of a school's vital elements in building their capacity.

Community connectedness within schools, for the purposes of this study, is defined as how school systems cultivate and promote networks and families' feelings of belonging within the school community. This study is unique because current models of family involvement processes do not necessarily account for the influence of community efficacy, interpersonal engagement, and participation in events. These three elements together provide understanding into how families' feelings of connectedness to a school community may impact their involvement with their child's education and their participation in events or activities at their child's school.

\subsection{Importance of Family Involvement and Participation}

Community connectedness within schools cannot be achieved without family involvement and participation. As an important contributor to children's learning and development, family involvement has been positively associated with academic outcomes and achievement throughout childhood and early adolescence (Arnold, Zeljo, Docroff, \& Ortiz, 2008; Domina, 2005; Mo \& Singh, 2008, Froiland, Peterson, \& Davison, 2012; McNeal, 2015; Toldson \& Lemmons, 2013). Families' involvement in their children's education takes many forms, which result in many different and evolving terms and definitions of parent and family engagement. While recognizing this conceptual heterogeneity, the current study focuses on a piece of family involvement, family participation, which is based on the work of Hoover-Dempsey and Sandler (1997). Hoover-Dempsey and Sandler (2005) consider the motivation behind a family member's choice to participate or not in a school community. Connectedness to the school community may be a key element within that choice.

Definitions of family participation in schools range from parents, guardian, or any family member volunteering in the child's classroom or on field trips to attending special school events or PTA meetings to participating in formal and informal conferences with school employees (e.g., teachers, school administration) (Hoover-Dempsey \& Sandler, 2005). Although, as discussed earlier, Epstein (2011) suggests family involvement is influenced by processes and complex relationships which makes it more complicated than simply attending events. While family involvement has different influences and interpretations, it has been found to significantly impact children's development within various domains including academic, social, and behavioral outcomes (Choi, Chang, Kim, \& Reio, 2015; Deckner, Adamson, \& Bakeman, 2006; Domina 2005; El Nokali, Bachman, \& Votruba-Drzal, 2010; Fernández-Alonso, Álvarez-Díaz, Woitschach, Suárez-Álvarez, \& Cuesta 2017; Garbacz, McDowall, Schaughency, Sheridan, \& Welch, 2015; Tichovolsky, Arnold, \& Baker, 2013; Weigel, Martin, \& Bennett, 2006).

Although family involvement and participation have been found to vary based on demographic characteristics (Park \& Holloway, 2013; Park, Stone, \& Holloway, 2017), the benefit of family involvement on children's development has not been limited to a specific race, ethnicity, or socioeconomic status (SES) (Zhang, Hsu, Kwok, Benz, \& Bowman-Perrott, 2011). For instance, Jeynes (2005) found that family involvement can lead to higher academic 
achievement no matter a child's race, SES, or gender. Overall, family participation in their child's school events has been found to enhance academic success for children regardless of gender, social class, and race-ethnicity memberships.

In order to better understand what creates environments that support children and families, the current study aims to gain a better understanding of the impact of the communities constructed within and between families and schools. By examining families' sense of connectedness to their child's school community, the purpose of the article is to investigate the relationship between connectedness and family participation in events and activities at their child's school.

\section{Methods}

\subsection{Participants, Recruitment and Data Collection}

Research has indicated that family involvement in a child's school community peaks during elementary education (El Nokali et al., 2010). Therefore, adult family members of elementary-aged children, kindergarten through fifth grade, attending primary schools across the United States were targeted for this study. Participants were recruited with the use of social media, as well as through email and distribution of informational letters from school representatives (i.e., teacher, administrator, etc.) and professional and personal contacts.

The online survey included questions regarding demographic characteristics, feelings of connectedness to their child's school community, and level of involvement and participation in the school community. Data were collected during late spring to allow for reflection across the school year. In the event that a family had more than one child in the targeted grade range, participants were asked to focus on the activities with their youngest child's school community. After performing regression diagnostics, outlined in more detail in the following section, the final sample $(n=215)$ consisted primarily of women $(n=188,87.4 \%)$ who identified as White, non-Hispanic $(n=198,92.1 \%)$ and who resided in the southeastern portion of the United States $(n=161,74.9 \%)$.

Table 1. Description of Sample

\begin{tabular}{|c|c|c|c|c|}
\hline Variable & $\mathrm{N}$ & $\%$ & Mean & SD \\
\hline \multicolumn{5}{|l|}{ Demographic Variables } \\
\hline \multicolumn{5}{|l|}{ Participant Gender } \\
\hline Male & 27 & 12.6 & & \\
\hline Female & 188 & 87.4 & & \\
\hline \multicolumn{5}{|l|}{ Race-Ethnicity } \\
\hline White or Caucasian & 198 & 92.1 & & \\
\hline Black or African American & 7 & 3.3 & & \\
\hline Hispanic or Latino & 4 & 1.9 & & \\
\hline Native American or Alaskan Native & 1 & .5 & & \\
\hline Native Hawaiian or Other Pacific Islander & 1 & .5 & & \\
\hline Multiracial & 4 & 1.9 & & \\
\hline \multicolumn{5}{|l|}{ U.S. Region of Residence } \\
\hline Southeastern States & 161 & 74.9 & & \\
\hline Southwestern States & 6 & 2.8 & & \\
\hline Northeastern States & 11 & 5.1 & & \\
\hline Midwestern States & 15 & 7.0 & & \\
\hline Western States & 16 & 7.4 & & \\
\hline \multicolumn{5}{|l|}{ Dependent Variable } \\
\hline Parental Involvement & & & 14.52 & 4.37 \\
\hline \multicolumn{5}{|l|}{ Independent Variable } \\
\hline Parent's Feeling of Connectedness & & & 39.74 & 9.22 \\
\hline \multicolumn{5}{|l|}{ Control Variables } \\
\hline \multicolumn{5}{|l|}{ Participant's Educational Attainment } \\
\hline Less than High School & 0 & 0 & & \\
\hline High School or GED & 14 & 6.5 & & \\
\hline Some College, 2-year/Vocational Degree & 41 & 19.1 & & \\
\hline Bachelor's Degree & 60 & 27.9 & & \\
\hline
\end{tabular}




\begin{tabular}{lcc}
\hline Some Graduate Work & 19 & 8.8 \\
Master's Degree & 53 & 24.7 \\
Doctoral Degree & 28 & 13.0 \\
Annual Income & & \\
Less than $\$ 5,000$ & 2 & .9 \\
$\$ 10,001-\$ 20,000$ & 2 & .9 \\
$\$ 20,001-\$ 30,000$ & 5 & 2.3 \\
$\$ 30,001-\$ 40,000$ & 8 & 3.7 \\
$\$ 40,001-\$ 50,000$ & 17 & 7.9 \\
$\$ 50,001-\$ 75,000$ & 52 & 24.2 \\
$\$ 75,001-\$ 100,000$ & 59 & 27.4 \\
Over $\$ 100,001$ & 66 & 30.7 \\
Child's Grade Level & & \\
Kindergarten & 52 & 24.2 \\
$1^{\text {st }}$ Grade & 39 & 18.1 \\
$2^{\text {nd }}$ Grade & 36 & 16.7 \\
$3^{\text {rd }}$ Grade & 37 & 17.2 \\
$4^{\text {th }}$ Grade & 22 & 10.2 \\
$5^{\text {th }}$ Grade & 29 & 13.5 \\
\hline
\end{tabular}

Table 1 further indicates that participants were of a relative high education and socioeconomic standing with $74.4 \%$ ( $n$ $=160)$ having a Bachelor's degree or higher and the majority $(n=125,58.1 \%)$ reporting an annual income greater than $\$ 75,000$. A full description of the sample can be found in Table 1. Children were distributed across grades: kindergarten $(n=52,24.2 \%)$, first grade $(n=39,18.1 \%)$, second grade $(n=36,16.7 \%)$, third grade $(n=37,17.2 \%)$, fourth grade $(n=22,10.2 \%)$, and fifth grade $(n=29,13.5 \%)$.

\subsection{Measures}

\subsubsection{Family Connectedness}

A family's sense of connectedness to their child's school community was measured using the Community Connections Index (Mancini et al., 2007). This measure consisted of set of 14 questions with Likert-type response options ranging from 1 "never" to 4 "often". Sample items within this measure included: Felt like you belonged in your child's school community and Talked with parents or teachers in your child's school community about your problems or difficulties. Internal consistency was high $(\alpha=.919)$ and responses were therefore combined to create an overall rating of family connectedness, ranging from 14 to 56 .

\subsubsection{Family Participation}

Participants responded to a set of six questions pertaining to the level of participation in their child's school community using Hoover-Dempsey and Sandler's (2005) Parents' Report of School-based Involvement Activities Scale, a Likert-type scale ranging from 1 "never" to 6 "almost every day." This measure was used to assess engagement in events such as parent/caregiver-teacher conferences, volunteering for special functions, attendance at special events and open-house. In the current project, internal consistency for this measure was moderately high $(\alpha=.792)$ and responses were therefore combined to create an overall rating of family participation ranging from 6 to 36 .

\subsection{Data Analysis}

Multiple regression techniques were used to examine the relationship between family participation in a child's school community and family's sense of connectedness to this community while controlling for family educational attainment, annual income, and child's grade level. The original dataset consisted of 218 participants. To enhance the validity of findings, regression diagnostics were conducted prior to final analyses to ensure data met the six assumptions of multiple regression testing regarding independence of errors, linearity, homoscedasticity, multicolinearity, influential outliers, and normality. Data were collected through the use of an anonymous online survey method where individuals participated by choice, generating no concerns over the potential relatedness of observations thereby meeting the assumption of independence of observations. After examining data graphically, no concerns for violations to linearity or homoscedasticity surfaced. Concerns regarding multicolinearity also did not surface after examining bivariate associations and values for tolerance. 
Case wise diagnostics revealed five potentially problematic cases in regards to influential outliers. In response to this, further investigation was taken by examining value for Cook's D and DFFITS. Three of the five cases of concern held the highest values for both Cook's D and DFFITS, further indicating violations to this assumption, and were therefore dropped from the dataset leaving the final adjusted sample as $n=215$. Lastly, data were graphically examined to assess violations to normality. Data were generally normally distributed with minor indications of a positive skew. Given the relative robustness of regression techniques to issues pertaining to non-normality in conjunction to graphical assessment of data, it was concluded that data transformation was not necessary.

\section{Results}

A multiple regression analysis was conducted to examine whether or not a family's sense of connectedness to their child's school community affected the degree to which they took part in the school community while controlling for participant educational attainment, annual income, and child's grade. The overall model was statistically significant, $F(4,195)=10.218, p<.05$, adj. $R^{2}=.16$, indicating that family participation was impacted by the associated variables.

Table 2. Multiple Regression Results for Parental Involvement

\begin{tabular}{lccc}
\hline & B & SE B & $\beta$ \\
\hline Independent Variable & & & \\
$\quad$ Participant's Feeling of Connectedness & $.17^{* *}$ & .03 & .40 \\
Control Variables & & & \\
$\quad$ Participant's Educational Attainment & $-.57^{*}$ & .20 & -.20 \\
$\quad$ Annual Income & -.07 & .11 & .04 \\
$\quad$ Child's Grade Level & -.24 & .17 & -.09 \\
\hline
\end{tabular}

${ }^{*} p \leq .01{ }^{* *} p \leq .001$

As show in Table 2, a one unit increase in feelings of connectedness was associated with a .17 unit increase in family participation $(t=5.40, p<.05)$ when controlling for participant educational attainment, annual income, and child's grade. In other words, the more the family member felt connected to his or her child's school community, the more likely they were to actively participate in the school community. Although included in the model as a control, family member's educational attainment $(t=-2.92, p<.05)$ was also significantly and negatively associated with level of participation indicating that more educated family members reported a lesser degree of participation in their child's school community. Annual income $(t=-1.24, \mathrm{p}=.22)$ was not significantly related to family participation. Likewise, child's grade level $(t=-1.45, p=.15)$ was not significantly related to family participation. Based on the standardized coefficient, family's feeling of connectedness to the school community had the largest effect on family participation.

\section{Discussion}

The current study explored whether feelings of community connectedness within a school environment was related to parent/caregivers' participation in their children's school community. As summarized earlier, previous research has demonstrated the impact family involvement can have on children's learning and development as well as the role schools play in getting family members to participate in activities and events. However, feeling connected to the school community has not been explored as related to participation specifically. This study demonstrated that connectedness is a component that needs to be considered when schools are assessing family participation. This finding is supported by Epstein's (2011) internal structure of the Influence of Family, School, and Community on Children's Learning theoretical model which notes the importance of family motivation in participation in school related activities. Implications for schools from the current study suggest that increasing family connectedness, which includes feelings of shared responsibility and the collective competence, may lead to increased family participation within the school; the target many schools use to measure family involvement. Separating implications by teachers and school administrators provides a context for the results in terms of role at the school. Implications of community connectedness on family participation are discussed below, first for teachers and then for school administration.

\subsection{Implications for Teachers}

Based on the findings of this study, when family members felt connected to a school community, there was a corresponding elevated level of participation in school events, which includes individual classroom/teacher activities. Within the classroom, formal networks between the teacher and the families, and informal networks between 
families, can influence families' connectedness to the community (Mancini \& Bowen, 2007). These relationships impact interactions, comfort level in schools, and overall participation. Bower and Griffin (2011) found teacher invitations may not effectively increase family involvement and participation without first having a relationship with the children's families. Because teachers have the ability to influence family's views of connectedness, they need to first build trust and respect with families to increase overall participation.

Building the connectedness within a specific classroom community can begin by simply understanding and respecting family preferences as well as cultural differences. By being aware of families' preferences, such as methods of obtaining information on their child's progress or preferred ways of being involved in the school community, teachers can demonstrate the value they place on the family's role in their child's life but also the family's role in the educational setting. Utilizing knowledge from the family, such as providing alternative times for an event because of a family member's schedule, allows for families to participate but also feel connected and respected within the formal network between the teacher and the parent. By utilizing families' preferences, considering their needs, and asking for their input, teachers may show families that they are respected and welcome in their child's school environment, which may strengthen the formal networks within the school community.

While teachers have more control over the formal networks within the classroom, they also may be able to strengthen the informal networks between the students' families. Connecting informally and building relationships between students' families can create a shared sense of responsibility for the success of children within their educational setting. Ideas to support this family to family connectedness include allowing for time for the families to meet and get to know each other. Informal networks between families can be supportive if families feel overwhelmed with participation requests from the school (Ferguson, Ramos, Rudo, \& Wood, 2008). Creating a welcoming environment for families to participate in events in the classroom and connecting families to each other can also further support those relationships between families (Hoover-Dempsey et al., 2005; Hoover-Dempsey et al., 2007). As Hoover-Dempsey and colleagues (2005) point out, this can be as straightforward as a physically welcoming appearance of the school and in inviting and respectful customer service when speaking with families. But beyond this, a welcoming environment is a place where families should feel safe, heard, and respected.

Teachers can also strengthen the community connectedness within their classroom by utilizing informal networks within a family, such as between a parent or other family member and a student. Others have noted the importance of using the informal networks within families such as having children personally invite their family members to school events rather than teachers as a way of increasing family participation (Green, Walker, Hoover-Dempsey, \& Sandler, 2007; Hoover-Dempsey \& Sandler, 1997). While teachers have much influence on building relationships with and between the families in classroom, the school as a whole needs to consider the importance of respecting and strengthening connectedness.

\subsection{Implications for Schools}

In addition to the work teachers are doing in their individual classrooms, school administrators need to be aware of how they are formally supporting families, teachers, and staff to build feelings of connectedness. Administrators can mobilize formal and informal networks within a school community to promote a family-centric model, including encouraging family events and modeling respect for family concerns (Mancini et al., 2007). While it may seem simple at first, a major way of building these networks is for administrators to get to know the teachers, staff, parents, and students who make up the networks within the school community. Hoover-Dempsey and colleagues (2005) called this creating positive assumptions about the importance of family involvement to children's outcomes. The belief that families play a key role must first be believed and respected for welcoming communities to be created.

Schools can benefit from recognizing that the ways in which families perceive the school community and their personal roles within that community differs. These perceptions vary based on personal experiences and cultural perspectives. Respecting and utilizing the unique beliefs and traditions that families bring into the school community is a step towards creating a school community that shows the value of family involvement. As schools empower families to move into leadership roles within the school community, families may further mobilize their networks, build their connectedness, and increase parent involvement and participation. For example, specifically asking families to join, share and take part in PTO, asking for family feedback directly on school policy based on their knowledge and life experiences, or reaching out of a family to help support the needs of another family are all ways to empower families to become more involved.

By providing families, teachers, and staff space to not only be heard, but to also get to know each other, administrators can build the foundation to both formal and informal networks. Offering information-sharing events, activities for community participation, and family-friendly gatherings focused on interpersonal engagement and 
building relational closeness of families outside of educational settings are all ways to nurture and strengthen a family's sense of connectedness to the school environment (Mancini \& Bowen, 2013).

Lastly, schools can move beyond just words to actually creating school policies that create family friendly environments. School policies that direct teachers and other staff should have an inherent and obvious commitment to a family friendly focus. Families should be viewed as partners in children's education rather than consumers of information only. Policies should be reviewed with staff, modeled by administration, and celebrated when staff are successful at building community. Policies that exist only as stagnant documents will shift schools to a family focused model but there must be corresponding actions.

Teachers, administrators, staff, and families are now tasked with building stronger connectedness within the school community. Although the actions of teachers and school administrators may be similar and should work in tandem with the other, each would have a different relationship with the families to build trust and hear concerns that together create a cohesive school community. This research implies that the first step in seeing growth in family participation in school events and activities is building a sense of community.

\subsection{Implications for Future Research}

This study not only expands upon previous research on family involvement in schools, but it also fills a gap in the literature by exploring how families' sense of connectedness to the school community relates to their participation. Researchers of community connectedness suggest that there may be different layers of connectedness, which would further the understanding of being connected to a community (Mancini et al., 2007). By parsing the various layers in school communities and understanding the potential differences in perceived types of family involvement, researchers could gain a better understanding of why families decide to be involved in their children's education. Within the school community, there are smaller communities that need to be explored in future research.

\subsection{Strengths and Limitations}

A strength in the current study was that the sample size was over 200 parents/caregivers. A sample of this nature allowed for some limited diversity within the study as represented by the inclusion of families from around the United States and children in a range of grades (i.e. kindergarten through fifth grade). Despite the size of the sample, a limitation was the demographic homogeneity of participants. The majority identified as white, higher income women with advanced degrees. Furthermore, this study was conducted through an online survey, which likely underrepresents those who lack resources for technology. Although a weakness of this study is the number of higher income families included in the sample, it also allows for better exploration of community connectedness within a specific population.

\section{Conclusion}

Past research has only minimally explored the impact of a family's feeling connected to a school community on self-reported levels of participation. Building off the research of Mancini and colleagues (2007) which focused on community connectedness in other types of communities, this study has included parent/caregiver perceptions of connectedness which further supports the importance of personalizing the school community.

To support family engagement, schools need to look beyond school-focused events and parent-teacher conferences to increasing families' feelings of connectedness to the school community. These come in the form of building formal and informal networks within and between families, teachers, and staff, and overall ensuring members feel like a valued part of the community. With an initial focus on creating connectedness, schools have the potential to not only increase quantifiable participation but also quality relationships that are the core to influencing children's educational and social outcomes.

\section{References}

Arnold, D. H., Zeljo, A., Docoroff, G. L., \& Ortiz C. (2008). Parent involvement in preschool: Predictors and the relation of involvement to preliteracy development. School Psychology Review, 37, 74-90.

Bird, K. (2006). Student information systems: How do you spell parental involvement? S-I-S. T.H.E. Journal, 33, $38-42$.

Bower, H., \& Griffin, D. (2011). Can the Epstein model of parental involvement work in a high-minority, high-poverty elementary school? A case study. Professional School Counseling, 15, $77-87$

Choi, N., Chang, M., Kim, S., \& Reio, T. G. (2015). A structural model of parent involvement with demographic and 
academic variables. Psychology in the Schools, 52(2), 154-167. https://doi.org/10.1002/pits.21813

Deckner, F. D., Adamson, L. B., \& Bakeman, R. (2006). Child and maternal contributions to shared reading: Effects on language and literacy development. Applied Developmental Psychology, 27, 31-41.

Domina, T. (2005). Leveling the home advantage: Assessing the effectiveness of parental involvement in elementary school. Sociology of Education, 78, 233-249.

El Nokali, N.E., Bachman, H.J., \& Votruba-Drzal, E. (2010). Parent involvement and children's academic and social development in elementary school. Child Development, 81, 988-1005. https://doi/org/10.1111/j.1467-8624.2010.01447.x

Epstein, J. (2011). School, family, and community partnerships: Preparing educators and improving schools Rev.Ed. Boulder, CO: Westview Press.

Ferguson, C., Ramos, M., Rudo, Z., \& Wood, L. (2008). The school family connection: Looking at the larger picture. Austin, TX: National Center for Family and Community Connections with Schools.

Fernández-Alonso, R., Álvarez-Díaz, M., Woitschach, P., Suárez-Álvarez, J., \& Cuesta, M. (2017). Parental involvement and academic performance: Less control and more communication. Psicothema, 29(4), 453-461. https://doi.org/10.7334/psicothema2017.181

Froiland, J. M., Peterson, A., \& Davison, M. L. (2012). The long-term effects of early parent involvement and parent expectation in the USA. School Psychology International, 34, 33-50. https://doi.org/10.1111/j.1467-8624.2010.01447.x

Garbacz, S. A., McDowall, P. S., Schaughency, E., Sheridan, S. M., \& Welch, G. W. (2015). A multidimensional examination of parent involvement across child and parent characteristics. The Elementary School Journal, 115(3), 384-406.

Green, C. L., Walker, J.M.T., Hoover-Dempsey, K. V., \& Sandler, H. M. (2007). Parents' motivations for involvement in children's education: An empirical test of a theoretical model of parent involvement. American Psychological Association, 99, 532-544. http://dx.doi.org/10.1037/0022-0663.99.3.532

Hoover-Dempsey, K. V., \& Sandler, H. M. (1997). Why do parents become involved in their children's education? Review of Educational Research, 67, 3-42. https://doi.org/10.3102/00346543067001003

Hoover-Dempsey, K.V., \& Sandler, H.M. (2005). Final Performance Report for OERI Grant \#R305T010673: The Social Context of Parental Involvement: A Path to Enhanced Achievement. Project Monitor, Institute of Education Sciences, U.S. Department of Education, March 22, 2005.

Jeynes, W.H. (2005). A meta-analysis of the relation of parental involvement to urban elementary school student academic achievement. Urban Education, 40, 237-269. https://doi.org/10.1177/0042085905274540

Mancini, J. A., \& Bowen, G. (2013). Families and communities: A social organization theory of action and change. In Peterson and K.R. Bush (eds.), Handbook of Marriage and the Family (pp. 781-813). New York: Springer

Mancini, J.A., Bowen, G.L., Ware, W.B., \& Martin, J.A. (2007). Engagement, participation, and community efficacy: Insights into social organization. Paper presented at the meeting of Hawaii International Meeting on the Social Sciences, Honolulu, HI.

McKenna, M. K., \& Millen, J. (2013). Look! Listen! Learn! Parent narratives and grounded theory models of parent voice, presence, and engagement in K-12 education. School Community Journal, 23(1), 9-48.

McNeal Jr, R. B. (2015). Parent involvement and student performance: The influence of school context. Educational Research for Policy and Practice, 14(2), 153-167. https://doi.org/10.13189/ujer.2014.020805

Mo, Y., \& Singh, K. (2008). Parents' relationships and involvement: Effects on students' school engagement and performance. Research in Middle Level Education, 31, 1-11.

Park, S., \& Holloway, D.S. (2013). No Parent Left Behind: Predicting Parental Involvement in Adolescents' Education Within a Socio demographically Diverse Population. The Journal of Educational Research, 106(2), 105-119. https://doi.org/10.1080/00220671.2012.667012

Park, S., Stone, S., \& Holloway, D.S. (2017). School-based parental involvement as a predictor of achievement and school learning environment: An elementary school-level analysis. Children and Youth Services Review, 82, 195-206. 
Ramirez, F. (2001). Technology and parental involvement. The Clearing House, 75, 30-31. https://doi.org/10.1080/00098650109599230?journalCode=vtch20

Smith, J., Wohlsetter, P., Kuzin, C.A., \& DePedro, K. (2011). Parent Involvement in urban charter schools: New strategies for increasing participation. The School Community Journal, 21, 71-94.

Selwyn, N., Banaji, S., Hadjithoma-Garstka, C., \& Clark, W. (2011). Providing a platform for parents? Exploring the nature of parental engagement with school Learning Platforms. Journal of Computer and Assisted Learning, 27, 314-323. https://doi.org/10.1111/j.1365-2729.2011.00428.x

Telem, M., \& Pinto, S. (2006). Information technology impact on school-parents and parents-student interrelations: A case study. Computers and Education, 47, 260- 279.

Tichovolsky, M. H., Arnold, D. H., \& Baker, C. N. (2013). Parent predictors of changes in child behavior problems. Journal of applied developmental psychology, 34(6), 336-345. https://doi.org/10.1016/j.appdev.2013.09.001

Toldson, I. A., \& Lemmons, B. P. (2013). Social demographics, the school environment, and parenting practices associated with parents' participation in schools and academic success among black, Hispanic, and white students. Journal of Human Behavior in the Social Environment, 23(2), 237-255. https://doi.org/10.1080/10911359.2013.747407

Weigel, D. J., Martin, S. S., \& Bennett, K. K. (2006). Contributions of the home literacy environment to preschool-aged children's emerging literacy and language skills. Early Child Development and Care, 176, 357-378.

Zhang, D., Hsu, H. Y., Kwok, O. M., Benz, M., \& Bowman-Perrott, L. (2011). The impact of basic-level parent engagements on student achievement: patterns associated with race/ethnicity and SES. Journal of Disability Policy Studies, 22(1), 28-39. https://doi.org/10.1177/1044207310394447 